\title{
O plano de trabalho de professores de Educação Física ex-participantes do Pibid/FEF/UFMT
}

\author{
Elaine Cristina Silvaid \\ Universidade do Estado do Mato Grosso, Cuiabá, MT, Brasil \\ Evando Carlos Moreirai"i(i) \\ Universidade Federal do Mato Grosso, Cuiabá, MT, Brasil
}

\begin{abstract}
Resumo
Considerando as vivências proporcionadas pelo Programa Institucional de Bolsas de Iniciação à Docência em relação ao planejamento nas aulas de Educação Física, teve-se como objetivo identificar as possíveis contribuições do subprojeto do Programa Institucional de Bolsa de Iniciação à Docência da Faculdade de Educação Física da Universidade Federal de Mato Grosso para o processo de planejamento do trabalho docente. Foi desenvolvida uma pesquisa qualitativa (BOGDAN; BIKLEN, 1994) com quatro professores de Educação Física da rede municipal de ensino de Cuiabá. O método utilizado foi o estudo de caso (FONSECA, 2002). O instrumento foi a entrevista semiestruturada. A análise e discussão dos dados respaldaram-se nos estudos realizados por Formosinho (2009), Imbernón (2011), Nóvoa (2009) e Tardif (2006). Os dados revelaram que as experiências proporcionadas pelo subprojeto ajudaram no sentido de saber como e quais referenciais podem servir de base para a elaboração do Plano de Trabalho docente, os possíveis conteúdos a serem selecionados, a importância da ação e reflexão sobre a prática pedagógica, bem como a organização e intencionalidade docente.
\end{abstract}

\section{Palavras-chave}

Planejamento. Educação Física. Pibid.

\section{Work plans of Physical Education teachers egresses from Pibid/FEF/UFMT}

\begin{abstract}
Considering the experiences provided by the Institutional Program for Teaching Initiation Scholarships in relation to planning in Physical Education classes, the objective was to identify the possible contributions of the subproject of the Institutional Program for Teaching Initiation Scholarship of the Faculty of Physical Education of Federal University of Mato Grosso for the teaching work planning process. A qualitative research was developed (BOGDAN; BIKLEN, 1994) with four Physical Education teachers from the municipal teaching network in Cuiabá. The method used was the case study (FONSECA, 2002). The instrument was the semi-structured interview. The analysis and discussion of the data were supported by studies carried out by Formosinho (2009), Imbernón (2011), Nóvoa (2009) and Tardif (2006). The data revealed that the experiences provided by the subproject helped in the sense of knowing how and which references can serve as a basis for the elaboration of the teaching Work Plan, the possible contents to be selected,
\end{abstract}

Educ. Form., Fortaleza, v. 6, n. 1, e2081, jan./abr. 2021

DOI: https://doi.org/10.25053/redufor.v6i1.2081

https://revistas.uece.br/index.php/redufor/index ISSN: 2448-3583 
the importance of the action and reflection on the pedagogical practice, as well as the teaching organization and intentionality.

\author{
Keywords \\ Planning. Physical Education. Pibid.
}

\title{
Plan de trabajo de los profesores de Educación Física exparticipantes del Pibid/FEF/UFMT
}

\begin{abstract}
Resumen
Considerando las experiencias brindadas por el Programa Institucional de Becas de Iniciación Docente en relación a la planificación en las clases de Educación Física, el objetivo fue identificar los posibles aportes del subproyecto del Programa Institucional de Becas de Iniciación Docente de la Facultad de Educación Física de la Universidad Federal de Mato Grosso por el proceso de planificación del trabajo docente. Se desarrolló una investigación cualitativa (BOGDAN; BIKLEN, 1994) con cuatro profesores de Educación Física de la red docente municipal de Cuiabá. El método utilizado fue el estudio de caso (FONSECA, 2002). El instrumento fue la entrevista semiestructurada. El análisis y discusión de los datos fue apoyado por estudios realizados por Formosinho (2009), Imbernón (2011), Nóvoa (2009) y Tardif (2006). Los datos revelaron que las experiencias aportadas por el subproyecto ayudaron en el sentido de saber cómo y qué referencias pueden servir de base para la elaboración del Plan de Trabajo docente, los posibles contenidos a seleccionar, la importancia de la acción y la reflexión sobre la práctica pedagógica, así como como la organización e intencionalidad docente.
\end{abstract}

Palabras clave

Planificación. Educación Física. Pibid.

\section{Introdução}

Este artigo apresenta dados parciais de uma dissertação de mestrado, cujo tema surgiu a partir da identificação de dificuldades e potencialidades relacionadas ao planejamento docente, vivenciadas por professores egressos do Programa Institucional de Bolsa de Iniciação à Docência da Faculdade de Educação Física da Universidade Federal de Mato Grosso (Pibid/FEF/UFMT).

O Pibid é uma política pública financiada pela Coordenação de Aperfeiçoamento de Pessoal de Nível Superior (Capes), em parceria com o Ministério da Educação, que desde 2007 vem desenvolvendo ações de aproximação dos futuros professores com o cotidiano escolar, proporcionando vivências e experiências metodológicas, tecnológicas e práticas (incluindo o planejamento), sobre a coordenação dos professores das Instituições de Ensino Superior e supervisão dos professores de escolas públicas (BRASIL, 2010). 
Entre as atividades desenvolvidas no subprojeto, foi realizado um planejamento participativo e interdisciplinar que resultou na elaboração de um Plano de Trabalho coerente com a realidade da comunidade e com os interesses dos estudantes. Entende-se que o planejamento é uma atividade de reflexão que assume a função de articular, organizar e coordenar a ação docente de acordo com os princípios e finalidades gerais da educação, bem como os anseios e dificuldades dos estudantes e do contexto social (LIBÂNEO, 1994).

No caso específico do planejamento da Educação Física, documentos em nível nacional, estadual e municipal, somados à produção do conhecimento da área, explicitam a importância de que os professores sejam capazes de expressar, de forma organizada, lógica e metódica, o quanto a disciplina tem a contribuir para o currículo escolar, colaborando para a sua legitimidade na Educação Básica (SOARES et al., 2012), o que não justifica uma ação docente desorganizada ou realizada sem propósito.

Levando-se em conta os objetivos do Pibid e as vivências proporcionadas pelo subprojeto Pibid/FEF/UFMT em relação ao planejamento escolar, definimos como objetivo para este trabalho identificar as possíveis contribuições do subprojeto Pibid/FEF/UFMT para o processo de planejamento do trabalho docente.

Esta é uma pesquisa qualitativa do tipo interpretativa. Para Bogdan e Biklen (1994), a pesquisa qualitativa possui cinco categorias principais: 1) considera o ambiente natural da pesquisa como fonte direta de dados; 2) incide na ideia de que toda pesquisa qualitativa é descritiva, uma vez que os dados resultam do registro de palavras escritas, imagens, documentos, entre outros; 3 ) tem o processo como mais importante do que o produto; 4) parte de questões mais amplas para questões específicas; e 5) atribui importância vital ao significado, cabendo ao pesquisador compreender o modo pelo qual as pessoas atribuem sentido às suas vidas.

A problemática investigada envolve um grupo específico de quatro professores que foram bolsistas do subprojeto Pibid/FEF/UFMT entre 2012 e 2016, assim assume-se o estudo de caso como método de pesquisa, tal como classificado por Fonseca (2002).

Estabeleceu-se como critério de inclusão: (a) ser licenciado em Educação Física; (b) ser professor efetivo do município de Cuiabá; e (c) ter sido bolsista do subprojeto Pibid/FEF/UFMT entre os anos de 2012 e 2016.

Educ. Form., Fortaleza, v. 6, n. 1, e2081, jan./abr. 2021 
Quanto aos instrumentos de coleta de dados, adotou-se a entrevista semiestruturada, que seguiu um roteiro de três perguntas relacionadas às experiências como bolsista do subprojeto Pibid/FEF/UFMT, as quais aconteceram em dias e horários previamente combinados entre 30 de abril e 18 de maio de 2018. O quadro a seguir apresenta a identificação das escolas dos participantes da pesquisa, gênero, período em que fez parte do subprojeto Pibid/FEF/UFMT, ano de conclusão do curso de licenciatura em Educação Física e de inserção na carreira profissional.

Quadro 1 - Sujeitos da pesquisa

\begin{tabular}{|c|c|c|c|c|c|}
\hline Escola & Participante & Gênero & $\begin{array}{c}\text { Período em que } \\
\text { participou do Pibid }\end{array}$ & $\begin{array}{c}\text { Ano de } \\
\text { conclusão }\end{array}$ & $\begin{array}{c}\text { Ano de inserção na } \\
\text { carreira profissional }\end{array}$ \\
\hline E1 & P1 & F & $2012-2016$ & 2016 & 2016 \\
\hline E2 & P2 & F & $2015-2016$ & 2016 & 2016 \\
\hline E3 & P3 & M & $2014-2016$ & 2016 & 2016 \\
\hline E4 & P4 & M & $2012-2014$ & 2016 & 2016 \\
\hline
\end{tabular}

Fonte: Construção da autora (2020).

O ingresso na carreira profissional dos participantes do estudo ocorreu em 2016, um ano antes do desenvolvimento da pesquisa. Para Huberman (2000), a fase de início de carreira corresponde aos três primeiros anos de docência, por essa razão pode-se classificá-los como professores iniciantes.

A pesquisa seguiu os critérios éticos necessários e teve o projeto aprovado no dia 11 de março de 2018 pelo Comitê de Ética em Pesquisa (CEP) da UFMT através do parecer número 2.536.887.

A análise e a discussão dos dados respaldaram-se nos estudos realizados por Formosinho (2009), Imbernón (2011), Nóvoa (2009) e Tardif (2006), bem como nas bases legais que regulamentam e dispõem sobre o Pibid e na interpretação que professores de Educação Física da rede municipal de ensino de Cuiabá expressam sobre a contribuição, limitação, desafios e influências do subprojeto Pibid/FEF/UFMT, nesse caso específico, no que se refere ao planejamento docente.

\section{O planejamento}

O planejamento faz parte do cotidiano das pessoas, nas mínimas tarefas diárias, em diversas áreas da vida, como trabalho, educação, finanças, entre outras. Segundo Gandin, D. e Gandin, L. (1999, p. 37), o planejamento: "[...] é o processo de divisar o 
futuro e agir no presente para construí-lo. Deste modo, planejar é organizar um conjunto de ideias que representem esse futuro desejado e transformar a realidade para que esse conjunto nela se realize no todo ou em parte".

Menegolla e Sant'Anna (1995), fundamentados em Martinez e Lahone (1977), compreendem o planejamento como um processo de previsão de necessidades, bem como de racionalização das condições (recursos, materiais, prazos) disponíveis para a conquista de objetivos. No contexto educacional, o planejamento tornou-se um poderoso meio de orientação intencional de ação, tanto para a reprodução como para a transformação da realidade e construção social. Para Luckesi (1994) e Vasconcellos (2000), cada uma dessas compreensões sobre a educação se relacionam com uma perspectiva de construção de sociedade e resulta em formas particulares de planejar e agir politicamente.

O planejamento é um processo obrigatório fixado no artigo 13 da Lei de Diretrizes e Bases da Educação Nacional, Lei o 9.394/1996, que resulta na materialização de planos, tais como: Plano Nacional de Educação, Planos Educacionais, Proposta Pedagógica da Escola e Plano de Trabalho Docente.

O Plano Nacional de Educação é o de maior abrangência; sua elaboração fica a cargo da União em colaboração com os estados, o Distrito Federal e os municípios; em seguida, os Planos Educacionais, produzidos e executados pelo estado, de acordo com as diretrizes, o Plano Nacional de Educação e as ações dos seus municípios; e, por fim, a Proposta Pedagógica da Escola (Projeto Político-Pedagógico') e os Planos de Trabalho, elaborados e desenvolvidos pelos professores (BRASIL, 1996).

Segundo Barbosa (2010), as escolas têm adotado basicamente três tipos de Plano de Trabalho: o Plano de Curso, o Plano de Unidade e o Plano de Aula. O Plano de Curso é o mais amplo da disciplina, por essa razão deve conter os elementos gerais para um ano ou semestre (BARBOSA, 2010; LIBÂNEO, 1994). No entendimento de Menegolla e Sant'Anna (1995, p. 64), o Plano de Curso nada mais é do que:

\footnotetext{
${ }^{1} \mathrm{Na}$ literatura encontramos diversas nomenclaturas correlatas ao Projeto Político-Pedagógico, como: Proposta Pedagógica, Plano Global de Médio Prazo, Plano da Escola, Plano Curricular, entre outras. Adotaremos o primeiro termo por entendermos que ele reforça as dimensões gerais (políticas, culturais, econômicas, entre outras) e específicas (comunitárias, administrativas e pedagógicas) que ele contempla (VASCONCELLOS, 2000).
}

Educ. Form., Fortaleza, v. 6, n. 1, e2081, jan./abr. 2021

DOI: https://doi.org/10.25053/redufor.v6i1.2081

https://revistas.uece.br/index.php/redufor/index 
[...] um instrumento para sistematizar a ação concreta do professor, a fim de que os objetivos da disciplina sejam atingidos. É a previsão dos conhecimentos e conteúdos que serão desenvolvidos na sala de aula, a seleção dos melhores procedimentos e técnicas de ensino, como também, dos recursos humanos e materiais que serão usados para um melhor ensino e aprendizagem. Além disso, o plano de disciplina propõe a determinação das mais eficazes técnicas e instrumentos de avaliação para verificar o alcance dos objetivos em relação à aprendizagem.

Quando bem elaborado o Plano de Curso, descarta-se a necessidade do Plano de Unidade, que segue a mesma lógica anterior, porém para um menor período de tempo. $\mathrm{O}$ Plano de Aula é o documento de maior detalhamento e objetividade dentro desse processo, dado que se trata da orientação sistematizada para uma condição didática entre professor, aluno e conteúdo (BARBOSA, 2010; LIBÂNEO, 1994; VASCONCELLOS, 2000).

Independentemente do nível de amplitude e complexidade, todos os documentos citados devem estar articulados de acordo com os princípios e finalidades gerais da educação ${ }^{2}$, servindo tanto como um instrumento de orientação de ações como de previsão de recursos e meios que atendam às suas reais necessidades (MENEGOLLA; SANT'ANNA, 1995).

Sendo o educando o fim último do processo educativo e o professor o principal responsável escolar pela mediação do ensino, faz-se necessário que ele (professor) reflita e tenha consciência crítica sobre o processo educacional e sobre a repercussão que suas ações terão na sociedade (MENEGOLLA; SANT'ANNA, 1995).

\section{O planejamento na Educação Física}

A Educação Física, como componente curricular da Educação Básica, tem o direito e o dever de integrar-se ao Projeto Político-Pedagógico da escola (BRASIL, 1996). Através dessa integração, os professores justificam o quanto e como a disciplina pode contribuir para o desenvolvimento pleno dos educandos.

Soares et al. (2012), ao proporem uma metodologia de ensino para a Educação Física Escolar numa perspectiva crítica, autônoma e transformadora, defendem uma concepção de currículo ampliado, comprometido com o Projeto Político-Pedagógico da

\footnotetext{
2 Segundo a Lei de Diretrizes e Bases da Educação Nacional, Lei o 9.394/1996, artigo 2ํ: "A educação, dever da família e do Estado, inspirada nos princípios de liberdade e nos ideais de solidariedade humana, tem por finalidade o pleno desenvolvimento do educando, seu preparo para o exercício da cidadania e sua qualificação para o trabalho".
}

Educ. Form., Fortaleza, v. 6, n. 1, e2081, jan./abr. 2021

DOI: https://doi.org/10.25053/redufor.v6i1.2081

https://revistas.uece.br/index.php/redufor/index 
escola, em que nenhuma disciplina se legitima de forma isolada. Para eles, é o tratamento articulado e sistematizado do conhecimento das diferentes áreas que permitirá ao aluno compreender, interpretar, constatar e explicar a realidade social.

Moreira e Pereira (2009), por exemplo, argumentam que a comunidade escolar possui maior entendimento do papel da Educação Física quando o professor se faz presente na elaboração e no cumprimento dos objetivos e estratégias estabelecidos pelo Projeto Político-Pedagógico da escola. Assim, cabe ao professor mediar intencionalmente suas práticas pedagógicas para que o saber acumulado e produzido ao longo da história da humanidade, através do jogo, da luta, da dança, do esporte, da ginástica, das manifestações corporais, entre outros (BRASIL, 1997), seja vivenciado crítica e conscientemente.

Quanto maior a participação e o envolvimento dos professores de Educação Física na elaboração do projeto, maior será a probabilidade de que as previsões estabelecidas pela comunidade venham a se materializar na sua prática pedagógica.

\section{O subprojeto Pibid/FEF/UFMT}

O Pibid tem estruturado seu funcionamento a partir de projetos institucionais, compostos por um ou mais subprojetos das diferentes áreas de conhecimento. Esses projetos são elaborados pelas Instituições de Ensino Superior e devem atender a uma série de critérios descritivos, estratégicos, avaliativos, organizacionais, conforme editais lançados pela Capes.

O subprojeto Pibid/FEF/UFMT iniciou suas ações em 2012, desse período até 2016 atuou efetivamente em duas escolas da rede estadual de Cuiabá. Sua proposta foi pensada no intuito de contribuir para a qualificação e valorização da formação inicial e continuada de professores licenciados em Educação Física com foco no Ensino Médio (UFMT, 2012, 2013).

Entre 2012 e 2016, o subprojeto Pibid/FEF/UFMT tomou por objetivo principal o fomento de experiências pedagógicas inovadoras ${ }^{3}$ e o fortalecimento da docência no

\footnotetext{
${ }^{3}$ Segundo Almeida (2017, p. 13), "[...] prática inovadora na Educação Física é aquela que consegue lidar, satisfatoriamente, com [...] o fato de a disciplina não se caracterizar por um saber sobre a cultura corporal de movimento, mas por uma ação pedagógica com ela. [...] Professores inovadores, portanto, são aqueles capazes, assim, de superar, ao menos um pouco, o vazio que se abriu entre 'o não mais e o
}

Educ. Form., Fortaleza, v. 6, n. 1, e2081, jan./abr. 2021

DOI: https://doi.org/10.25053/redufor.v6i1.2081

https://revistas.uece.br/index.php/redufor/index ISSN: 2448-3583 
Ensino Médio. Para tanto, realizou estratégias de ação diagnóstica e de intervenção voltadas à compreensão crítico-reflexiva da realidade, num trabalho complementar e inter-relacionado entre universidade-escola, docentes-discentes e teoria-prática (UFMT, 2012, 2013).

As atividades do subprojeto incluíram o desenvolvimento de ações didático-pedagógicas na escola, participação e publicação em eventos científicos, além de reuniões semanais de estudo, troca de experiências, planejamento, diálogos sobre as dificuldades das/nas escolas, apresentação de seminários temáticos, estudo de artigos científicos e documentos referenciais da Educação e da Educação Física.

Quanto ao planejamento, as propostas vigentes na época previam a construção de um Plano de Trabalho participativo e interdisciplinar, que tivesse por referência 0 Projeto Político-Pedagógico da escola, a proposta do subprojeto Pibid/FEF/UFMT, bem como a opinião dos estudantes de Educação Física do Ensino Médio.

Diante do exposto, com o propósito de identificar as possíveis contribuições do subprojeto Pibid/FEF/UFMT para o processo de planejamento do trabalho docente de professores de Educação Física egressos do programa, realizaram-se as seguintes indagações: "1) Como foi elaborado o planejamento das aulas de Educação Física no Pibid?"; "2) Como foi sua experiência como bolsista Pibid?"; "3) Você entende que o Pibid contribuiu para a sua formação inicial? Como isso se deu? Pode dar algum exemplo?".

Quanto à elaboração do planejamento das aulas de Educação Física no subprojeto Pibid/FEF/UFMT, os professores relataram que, entre 2012 e 2016, as duas escolas parceiras do subprojeto não disponibilizaram o Projeto Político-Pedagógico, apenas o Plano de Curso da disciplina. Ter acesso ao Projeto Político-Pedagógico das escolas torna-se, muitas vezes, uma tarefa difícil, apesar de teoricamente se tratar de um documento público, que deve estar disponível à comunidade. A sua ausência indica possíveis fragilidades nos diversos setores que constituem a vida escolar, por exemplo, a articulação e inter-relação de cada disciplina com os andamentos gerais da instituição.

No tocante ao Plano de Curso, os professores argumentaram que, em ambos os casos, o documento previa a oferta de quatro modalidades esportivas coletivas (handebol,

ainda não', para lembrar aqui da metáfora cunhada por Fensterseifer e González (2007) ao se referirem ao status da Educação Física após a ruptura com sua tradição".

Educ. Form., Fortaleza, v. 6, n. 1, e2081, jan./abr. 2021

DOI: https://doi.org/10.25053/redufor.v6i1.2081

https://revistas.uece.br/index.php/redufor/index 
vôlei, futsal e basquete), organizadas por bimestre, dinâmica que é alvo de crítica por autores como Darido e Rangel (2005), Kawashima (2018) e Moreira e Pereira (2009).

$\mathrm{O}$ relato da professora P2 exemplifica as ações de planejamento nas duas escolas:

[...] a professora sentou, explicou tudo que a gente tinha que fazer, [...] ela falou que a gente tinha que conhecer o planejamento que tinha na escola, então a gente foi lá e observou, viu o planejamento, discordou, [...] mas respeitou o que tinha e tinha que construir o nosso próprio cronograma.

Dessas experiências, os ex-bolsistas proporcionaram pensamentos, ações e apropriações de valores para além das práticas esportivas, voltados à compreensão crítico-reflexiva da realidade, como a problematização do espaço da mulher e do homem em determinados esportes, a influência da mídia na visibilidade de atletas, as marcas e modalidades esportivas, os impactos econômicos, estruturais e sociais da Copa do Mundo FIFA de 2014 em Cuiabá, o doping esportivo, o uso de recursos tecnológicos no esporte, dentre outros, contemplando o que Moreira e Pereira (2009) destacam como positivo para formar um aluno emancipado, apto a realizar escolhas e tarefas próprias.

[...] eu vejo que o Pibid buscava trazer sentido dessa prática, para que o aluno visse sentido naquilo que ele estava fazendo, que aquilo poderia servir para ele em alguma coisa futuramente ou para que ele pudesse respeitar mais a Educação Física como ela merece, para que ela pudesse ter a sua valorização, [...] sua legitimidade dentro da escola. (P1).

Para Kawashima (2018), a partir do momento que o estudante consegue identificar e interpretar os sentidos da realidade, ele consegue compreender algo nas aulas de Educação Física e consequentemente utilizar esse conhecimento em sua vida. Assim, os ex-bolsistas se comprometeram a planejar e desenvolver um trabalho significativo na escola que realmente desconstruísse a imagem equivocada de disciplina descomprometida, recreacionista e repetitiva.

Após os primeiros encontros de estudo, observações e definição dos conteúdos, a professora/coordenadora do subprojeto, junto dos ex-bolsistas, organizou como seriam elaborados e executados os Planos de Aula. A dinâmica de intervenção nas escolas ocorreu de acordo com o número de bolsistas e a estrutura das escolas parceiras. De 2012 a 2014, quando houve o envolvimento de dez bolsistas no subprojeto, os planos foram organizados em duplas ou trios, e as aulas ocorriam em contraturno escolar no 
período vespertino, divididas por gênero (feminino e masculino) e organizadas por ano (1ํ $\left.A, B, C \ldots 2^{\circ} A, B, C \ldots\right)$.

De 2015 a 2016, quando o subprojeto iniciou suas ações em outra instituição, com dois professores/supervisores e quinze bolsistas, foi possível organizá-los sozinhos ou em duplas. As aulas foram ofertadas no turno regular, no período vespertino, sendo que cada turma possuía um horário específico, sem distinção de gênero.

Sobre a dinâmica de elaboração e desenvolvimento dos Planos de Aula, os professores disseram o seguinte: "[...] teve época que trabalhou sozinho e trabalhou em dupla. [...] O tema era o vôlei; a gente distribuía tudo que ia trabalhar no vôlei no bimestre inteiro, como que seria a sequência" (P2).

Quanto às reuniões semanais realizadas pelo subprojeto, os professores foram unânimes em dizer que elas serviam para expor dificuldades e acertos, trocar ideias e experiências com os colegas, bem como refletir sobre a própria prática e o processo de ensino e aprendizagem dos estudantes.

A gente fazia como se fosse passar um feedback. [...] É uma reflexão em cima daquilo lá que era executado na escola. [...] Contribuía porque eram várias experiências, então cada pessoa levava o seu lá e depois podia tentar, [...] aprendia também ouvindo os outros. (P3).

Segundo a professora P2, a reflexão sobre a prática realizada no Pibid/FEF/ UFMT era bastante pontual em discutir por que não havia dado certo ou em pensar como fariam para que os alunos do Ensino Médio entendessem o conteúdo de forma bem construída no tempo que dispunham.

Para Nóvoa (2009) e Tardif (2006), é justamente a exposição a situações de incertezas, contextualizadas e únicas, solucionadas por meio da investigação, que fará dos futuros professores profissionais prático-reflexivos, produtores de saberes específicos do seu próprio trabalho. Dessa forma, a prática profissional é vista como um "[...] espaço original e relativamente autônomo de aprendizagens e de formação para os futuros práticos, bem como um espaço de produção de saberes e de práticas inovadoras pelos professores experientes" (TARDIF, 2006, p. 286).

No tocante às experiências proporcionadas pelo subprojeto Pibid/FEF/UFMT, a professora P1 considera que o subprojeto representou a melhor parte do curso de graduação, momento em que ela pôde ler e (re)ler textos, documentos referenciais, 
livros, entre outros, que havia conhecido na graduação de maneira aprofundada e orientada. Essa atividade antecedeu a entrada na escola e favoreceu a organização, execução e reflexão das ações.

[...] antes de a gente ir para a escola, teve toda essa preparação [...] em relação à leitura do que é currículo, em relação ao planejamento. [...] Era como se acontecesse uma semana pedagógica nos encontros do Pibid; era o momento que a gente sentava e discutia em torno de que conteúdo ia ser trabalhado, como que a gente iria fazer essa abordagem com os alunos nesse período e a possibilidade. (P1).

Essa possibilidade também partiu do interesse dos estudantes:

Tanto que essa questão de ver o que o aluno quer fazer eu vi e aprendi lá no Pibid, quando a gente aplicou questionário para saber quais práticas os alunos queriam fazer ou gostavam de fazer. A partir daí, a gente passou a abrir um leque de possibilidades para poder trabalhar, isso foi muito bacana. (P1).

As experiências citadas pela professora P1 apontam o embasamento teórico, o estudo do planejamento e o questionário diagnóstico dos estudantes como estratégias preliminares de ação. Para Moreira (2009), o planejamento conjunto pode expressar as verdadeiras intenções do grupo e do professor, o que, por conseguinte, gerará nos educandos a corresponsabilidade pela prática e a sua valorização.

Para o professor P3, as experiências no subprojeto Pibid/FEF/UFMT também foram importantes na avaliação do trabalho executado: "[...] porque, além de a gente ter base, saber por que está ensinando [...], você vê realmente se você alcançou o objetivo ou não através daquilo". Tal percepção corrobora a ideia de que a avaliação serve como elemento de reflexão contínua sobre a prática, que possibilita a adaptação de instrumentos de trabalho e a retomada de aspectos que precisam ser revistos, ajustados, reconhecidos e adequados ao processo de aprendizagem individual ou coletivo (BRASIL, 1997).

Percebe-se que as reuniões orientadas pelas professoras que coordenaram o subprojeto Pibid/FEF/UFMT serviram como espaço de discussão e reflexão dos ex-bolsistas sobre suas ações, exercício que, para o professor P4, estabeleceu a ligação entre a universidade com mundo real da escola: "O Pibid era teoria e prática, fazia essa ponte, levava a universidade para dentro da escola, mas tendo feedback também. A gente tentava ir com um conhecimento lá e voltava com o conhecimento da escola". 
Dessa estreita relação de ir e vir entre a academia e a escola, os ex-bolsistas experienciavam alternativas de ação e depois discutiam, trocavam ideias, refletiam, no sentido de potencializá-las: "O Pibid propiciava você tentar coisas [...] que pudessem dar certo, te propiciava ver os colegas tentando outras coisas e aprender com o que eles estavam fazendo também, então eu acho que foi uma experiência muito rica" (P4).

Segundo Formosinho (2009), é a partir da reflexão dos saberes específicos do seu trabalho que o professor adquirirá autonomia para decidir sobre suas práticas e seus objetivos, partilhar e aperfeiçoar experiências, bem como introduzir inovações passíveis de aumentar sua eficácia. De tal modo, para Tardif (2006), a prática profissional não é instituída como um campo simples de aplicação de teorias elaboradas fora dela, mas como campo amplo de mobilização, produção e transmissão de saberes e competências que emergem da própria prática. "As escolas tornam-se, assim, lugares de informação, de inovação, de experimentação e de desenvolvimento profissional, mas também, idealmente, lugares de pesquisa e de reflexão crítica" (TARDIF, 2006, p. 280).

De acordo com dados de pesquisa realizada por Gatti et al. (2014) sobre estudos que abordaram a temática do Pibid em diferentes áreas, a parceria entre a universidade e a escola tem de fato apresentado resultados exitosos ao concretizar ações de reflexão, colaboração e desenvolvimento de estratégias de aprendizagem. Nesse contexto proporcionado pelo Pibid/FEF/UFMT, a experimentação de métodos e estratégias diversificados no trato dos conteúdos da Educação Física Escolar fez com que os ex-bolsistas ampliassem seu entendimento sobre a área e suas possibilidades de ação:

A partir do Pibid, eu comecei a ver a Educação Física de uma forma diferente do que eu conhecia, que era trabalhar o quarteto (vôlei, basquete, handebol e futsal), por exemplo, eu posso trabalhar o quarteto, mas de formas diferentes, [...] eu posso fazer uma evolução [...] ou até mesmo explorar. (P1).

[...] a parte melhor da experiência foi a gente mostrar o que a Educação Física tem, que não é só ir lá e fazer a prática, é pensar o que significa, [...] vê-la de várias formas diferentes [...], porque a gente ocupou não foi só uma quadra, a gente ocupou o que podia na escola. (P2).

O Pibid já era mais legal, [...] a gente deu aula de nutrição, deu aula de futsal, deu aula sobre a Copa, então passamos por vários assuntos. (P3).

Formosinho (2009) considera as práticas de ensino como espaços valorosos para a experimentação de métodos e técnicas diferentes dos já observados no currículo

Educ. Form., Fortaleza, v. 6, n. 1, e2081, jan./abr. 2021

DOI: https://doi.org/10.25053/redufor.v6i1.2081

https://revistas.uece.br/index.php/redufor/index 
discente, pois permitem que o repertório de experiências seja alargado e possivelmente transferido para o desempenho docente.

Quando questionadas sobre outras experiências importantes proporcionadas pelo subprojeto, as professoras P1 e P2 citaram o trabalho interdisciplinar que o Pibid/ FEF/UFMT desenvolveu junto ao Pibid de Filosofia: "Ah! Uma coisa muito bacana foi [...] a palestra com o professor da outra disciplina; a gente levou o professor lá da faculdade e falou do futebol numa outra visão". Na época, os dois subprojetos discutiram com os estudantes do Ensino Médio o filme Offside (Fora do jogo), lançado em 2006 pelo iraniano Jafar Panahi, que trata do impedimento de mulheres iranianas assistirem a partidas de futebol no país, problematizando o papel da mulher no esporte e na sociedade.

Para Imbernón (2011), as experiências interdisciplinares permitem aos futuros professores assimilar os conhecimentos e os procedimentos de outras disciplinas, a partir da discussão e análise crítica de temas que refletem a realidade educativa.

Os professores também destacaram a pesquisa, a participação em eventos e a publicação de trabalhos como experiências de reflexão e troca de saberes importantes para a melhoria da prática pedagógica. Segundo Nóvoa (2009), o registro escrito das vivências pessoais e profissionais é essencial na aquisição de consciência do próprio trabalho e para a construção da identidade docente. Além disso, consoante Imbernón (2011), a reflexão prático-teórica desenvolve no professor a capacidade de gerar conhecimento pedagógico sobre sua própria prática.

Quando questionada acerca da contribuição do Pibid/FEF/UFMT para seu processo de formação inicial, a professora P2 destacou que o subprojeto foi fundamental para que ela pudesse planejar o seu trabalho na escola:

\section{[...] porque na disciplina de Didática eu não aprendi, eu não sabia o que eu estava fazendo, eu não tinha noção da importância das coisas, por exemplo, o meu planejamento anual do ano passado [...] eu não sabia como colocar no papel, eu não sabia como organizar; para eu fazer o meu, mudei um pouco a estrutura, mas [...] peguei o do Pibid e olhei como que a gente tentou organizar.}

$\mathrm{Na}$ concepção do professor $\mathrm{P} 3$, as experiências no Pibid/FEF/UFMT possibilitaram realmente o contato com a prática pedagógica na escola, o que contribuiu com a formação de uma maneira geral e também com o seu planejamento: "[...] para onde eu estou, na rede pública municipal, contribuiu só no sentido de explicar um pouco

Educ. Form., Fortaleza, v. 6, n. 1, e2081, jan./abr. 2021

DOI: https://doi.org/10.25053/redufor.v6i1.2081

https://revistas.uece.br/index.php/redufor/index 
sobre o planejamento [...], aonde eu posso recorrer, em quem que eu trabalho isso, como, as possibilidades de trabalho dos conteúdos".

Contudo, por mais que a vivência tenha sido com estudantes do Ensino Médio, o contato com leituras no grupo de estudo também ajudou na busca de referências para as aulas: "[...] os professores passaram todos aqueles autores que poderiam ajudar na nossa prática, nós conhecemos tanto pessoalmente quanto por leituras" (P1). Segundo a professora $\mathrm{P} 1$, as experiências contribuíram para a troca de conhecimentos e ampliação das possibilidades de ação na escola: "[...] o Pibid me ajudou a enxergar o leque dos conteúdos que eu posso trabalhar na escola".

Por fim, o professor P4 destaca que o Pibid/FEF/UFMT foi fundamental na sua formação inicial e na sua prática profissional:

\begin{abstract}
[...] ele foi determinante, eu tenho certeza disso, ele determinou a minha função. Se não fosse o Pibid, eu ia ter outra concepção de educação e outra concepção de como aplicar. A graduação eu acho que não daria conta de me preparar para estar na escola; eu me sinto preparado hoje. Acho que tem uma série de coisas para aprender, tem uma série de equívocos que eu faço ainda, mas eu me sinto preparado por conta do Pibid, não é por conta da graduação.
\end{abstract}

Diante do exposto, deduzimos que a participação dos professores no subprojeto Pibid/FEF/UFMT com os estudantes do Ensino Médio permitiu que tivessem acesso a experiências voltadas à compreensão crítico-reflexiva da realidade, a partir de questões originadas da/na própria prática pedagógica. Com isso, estabeleceu a aproximação entre a universidade e a escola, a teoria e a prática, os docentes e os discentes. Ainda forneceu condições para o desenvolvimento da autonomia e da identidade profissional.

Para Ramos et al. (2015), o Pibid possibilita a aprendizagem não só dos bolsistas, mas dos profissionais envolvidos na escola e na universidade. Proporciona espaços de debates acerca de questões pertinentes ao ambiente escolar, à Educação Física e à formação de professores.

Gatti et al. (2014, p. 60) teorizam que: "Os licenciandos valorizam essa aproximação como algo social e educacionalmente relevante, como se o Pibid fosse uma porta que permitiu/obrigou as instituições de ensino superior, suas licenciaturas e professores a interagir com a rede escolar pública".

Perassolli e Alves (2015, p. 23, grifo nosso) indicam em seus estudos com licenciandos participantes do Pibid que as experiências do programa foram muito 
significativas, "[...] por exemplo, a compreensão da rotina escolar (funcionamento da escola), regras de convívio, a ação de planejar e seus limites e possibilidades, a relação teoria e prática".

Conforme os professores pesquisados, o subprojeto auxiliou também na ampliação dos conteúdos da disciplina na escola e sua forma de organização, além de possibilitar o contato com outra área do conhecimento, numa perspectiva interdisciplinar.

Obviamente não podemos encarar o Pibid como a solução de todas as deficiências formativas dos professores, mas devemos reconhecer que ele representa um espaço valoroso de aquisição dos sabres e competências inerentes ao desempenho docente.

\section{Considerações finais}

Programas como o Pibid têm buscado elevar a qualidade da formação inicial e continuada de professores, proporcionando vivências e experiências práticas inovadoras, mais próximas da realidade. Entre os saberes fundamentais do trabalho docente, está o planejamento, por onde os professores devem articular, organizar e coordenar suas ações.

Considerando as vivências proporcionadas pelo subprojeto Pibid/FEF/UFMT em relação ao planejamento na formação inicial de quatro professores de Educação Física, foi proposto neste artigo identificar as possíveis contribuições do Pibid/FEF/UFMT para o processo de planejamento do trabalho docente de professores de Educação Física egressos do programa. Identificou-se que as experiências proporcionadas pelo subprojeto Pibid/FEF/UFMT ajudaram no sentido de saber como e quais referenciais podem e devem servir de base para a elaboração dos planos, quais conteúdos, a importância da ação e reflexão sobre a prática, bem como da interdisciplinaridade, da organização de ações e da intencionalidade docente.

Esperamos que esta pesquisa colabore para que os professores identifiquem os fatores positivos e os que podem ser melhorados com relação ao seu planejamento nas aulas de Educação Física, bem como aos demais professores da área, de modo que reconheçam e efetivem um Plano de Trabalho coerente, articulado, crítico, intencional, flexível, vivo, que proporcione um aprendizado significativo aos estudantes. Enfim, avaliamos que o Pibid é, sem dúvida, um programa valoroso e que contribuiu para a formação desses profissionais. 


\section{Referências}

ALMEIDA, F. Q. Educação Física Escolar e práticas pedagógicas inovadoras: uma revisão. Corpoconsciência, Cuiabá, v. 21, n. 3, p. 7-16, 2017.

BARBOSA, C. L. A. Educação Física e Didática: um diálogo possível e necessário. Petrópolis: Vozes, 2010.

BOGDAN, R. C.; BIKLEN, S. K. Investigação qualitativa em educação: uma introdução à teoria e aos métodos. Porto: Porto, 1994.

BRASIL. Decreto no 7.219, de 24 de junho de 2010. Dispõe sobre o Programa Institucional de Bolsa de Iniciação à Docência - PIBID e dá outras providências. Diário Oficial [da] República Federativa do Brasil, Poder Executivo, Brasília, DF, 25 jun. 2010.

BRASIL. Lei no 9.394, de 20 de dezembro de 1996. Estabelece as Diretrizes e Bases da Educação Nacional. Diário Oficial [da] República Federativa do Brasil, Poder Executivo, Brasília, DF, 21 dez. 1996.

BRASIL. Parâmetros Curriculares Nacionais. Brasília, DF: MEC/SEF, 1997.

DARIDO, S. C.; RANGEL, I. C. A. Educação Física na escola: implicações para a prática pedagógica. Rio de Janeiro: Guanabara Koogan, 2005.

FONSECA, J. J. S. Metodologia da pesquisa científica. Fortaleza: UEC, 2002.

FORMOSINHO, J. (coord.). Formação de professores: aprendizagem profissional e acção docente. Porto: Porto, 2009.

GANDIN, D.; GANDIN, L. A. Temas para um projeto político-pedagógico. 4. ed. Petrópolis: Vozes, 1999.

GATTI, B. A. et al. Um estudo avaliativo do Programa Institucional de Bolsa de Iniciação à Docência (Pibid). São Paulo: FCC/SEP, 2014.

HUBERMAN, M. O ciclo de vida profissional dos professores. In: NÓVOA, A. (org.). Vida de professores. 2. ed. Porto: Porto, 2007. p. 31-78.

IMBERNÓN, F. Formação docente e profissional: formar-se para a mudança e incerteza. 9. ed. São Paulo: Cortez, 2011.

JARDILINO, J. R.; SAMPAIO, A. M. Desenvolvimento profissional docente: Reflexões sobre política pública de formação de professores. Educação \& Formação, Fortaleza, v. 4 , n. 10, jan./abr., p. 180-194, 2019. Disponível em: https://revistas.uece.br/index.php/redufor/article/view/848/1089. Acesso em: 02 jan. 2019.

Educ. Form., Fortaleza, v. 6, n. 1, e2081, jan./abr. 2021

DOI: https://doi.org/10.25053/redufor.v6i1.2081

https://revistas.uece.br/index.php/redufor/index 
KAWASHIMA, L. B. Sentidos e significados da Educação Física para os alunos do IFMT - campus São Vicente: a pesquisa-ação como forma de construção coletiva de conhecimento. 2018. 723 f. Tese (Doutorado em Educação) - Programa de Pós-Graduação em Educação, Universidade Federal de Mato Grosso, Cuiabá, 2018.

LIBÂNEO, J. C. Didática. São Paulo: Cortez, 1994.

LIMA, A.; AZEVEDO, M. L. Processo de institucionalização da política nacional e estadual de formação docente: Proposições e resistências no Paraná. Educação \& Formação, v. 4, n. 3, p. 124-147, 2019. Disponível em:

https://revistas.uece.br/index.php/redufor/article/view/1126/1311. Acesso em: 10 out. 2020.

LUCKESI, C. C. Filosofia da educação. São Paulo: Cortez, 1994.

MARTINEZ, M. J.; LAHONE, C. O. Planejamento escolar. São Paulo: Saraiva, 1977.

MATO GROSSO. Orientações curriculares: área de Linguagens: Educação Básica. Cuiabá: Seduc, 2010.

MENEGOLLA, M.; SANT'ANNA, I. M. Por que planejar? Como planejar. 3. ed. Petrópolis: Vozes, 1995.

MOREIRA, E. C.; PEREIRA, R. S. A Educação Física na construção do projeto político-pedagógico da escola. In: MOREIRA, E. C. (org.). Educação Física escolar: desafios e propostas. 2. ed. Jundiaí: Fontoura, 2009. p. 21-42.

NÓVOA, A. Professores: imagens do futuro presente. Lisboa: Educa, 2009.

OFFSIDE. Direção: Jafar Panahi. Intérpretes: Shayesteh Irani, Sima MobarakShahi, Ayda Sadeqi e outros. Roteiro: Jafar Panahi, Shadmehr Rastin. Música:Koorosh Bozorgpour. Produzido por: Sony pictures classics. Irã. 2006, 1 DVD (86 min.).

PERASSOLLI, M. A.; ALVES, F. D. As contribuições do Pibid para a formação inicial na docência em Educação Física. In: ALVES, F. D.; RAMOS, G. N. S.; SOUZA JÚNIOR, O. M. (org.). Formação inicial de professores de Educação Física: experiências do Pibid/UFSCar. Curitiba: CRV, 2015. p. 17-30.

RAMOS, G. N. S. et al. O Pibid como espaço de formação compartilhada: aprendendo na e com a convivência. In: ALVES, F. D.; RAMOS, G. N. S.; SOUZA JÚNIOR, O. M. (org.). Formação inicial de professores de Educação Física: experiências do Pibid/UFSCar. Curitiba: CRV, 2015. p. 88-102.

SOARES, C. L. et al. Metodologia do ensino de Educação Física. 2. ed. São Paulo: Cortez, 2012.

SOUSA, E.; MARQUES, E. O processo de constituir-se professor na relação objetividade-subjetividade: significações acerca da mediação social na escolha pela docência. Educação \& Formação, Fortaleza, v. 4, n. 11, maio/ago., p. 82-96, 2019. 
Disponível em: https://revistas.uece.br/index.php/redufor/article/view/841/1143. Acesso em 02 mai. 2019.

TARDIF, M. Saberes docentes e formação profissional. 7. ed. Petrópolis: Vozes, 2006.

UFMT - Universidade Federal de Mato Grosso. Detalhamento do subprojeto

Pibid/FEF/UFMT. Cuiabá: UFMT, 2012.

UFMT - Universidade Federal de Mato Grosso. Detalhamento do subprojeto Pibid/FEF/UFMT. Cuiabá: UFMT, 2013.

VASCONCELLOS, C. S. Planejamento: projeto de ensino-aprendizagem e projeto político-pedagógico: elementos metodológicos para elaboração e realização. 7. ed. São Paulo: Libertad, 2000.

VASCONCELLOS, K. R.; BERNARDO, E. Profissionalização docente: reflexões e perspectivas no Brasil. Educação \& Formação, v. 1, n. 2, p. 208-222, 2016. Disponível em: https://revistas.uece.br/index.php/redufor/article/view/109/91. Acesso em: 10 out. 2020.

Elaine Cristina Silva, Universidade do Estado do Mato Grosso, Faculdade de Ciências da Saúde iDhttps://orcid.org/0000-0002-2104-9589

Mestra. Universidade do Estado de Mato Grosso (Unemat), Faculdade de Ciências da Saúde. Participa do Grupo de Estudos e Pesquisas em Educação Física Escolar e Práticas Pedagógicas (Geefe).

Contribuição de autoria: Concepção do texto.

Lattes: http://lattes.cnpq.br/2384753156636588

E-mail: ecsacademico@gmail.com

\author{
Evando Carlos Moreira, Universidade Federal de Mato Grosso, Departamento de Teoria e \\ Fundamentação \\ ii Dhttps://orcid.org/0000-0002-5407-7930 \\ Pós-doutor. Universidade Federal de Mato Grosso (UFMT), Departamento de Teoria e Fundamentação. \\ Líder do Grupo de Estudos e Pesquisas em Educação Física Escolar e Práticas Pedagógicas (Geefe). \\ Contribuição de autoria: Correção do texto. \\ Lattes: http://lattes.cnpq.br/4561814544149415 \\ E-mail: ecmmoreira@uol.com.br
}

Editora responsável: Lia Machado Fiuza Fialho Pareceristas ad hoc: Paulo Sérgio Corrêa e Ozenira Oliveira

\title{
Como citar este artigo (ABNT):
}

SILVA, Elaine Cristina; MOREIRA, Evando Carlos. O plano de trabalho de professores de Educação Física ex-participantes do Pibid/FEF/UFMT. Educ. Form., Fortaleza, v. 6, n. 1, e2081, 2020. Disponível em: https://revistas.uece.br/index.php/redufor/article/view/2081 


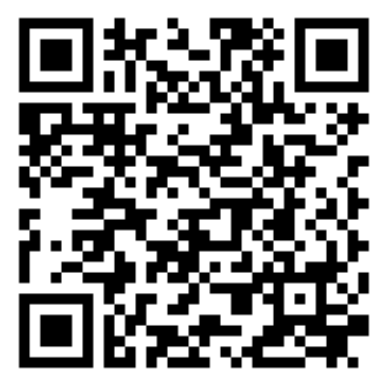

Recebido em 3 de março de 2020.

Aceito em 20 de julho de 2020.

Publicado em 30 de outubro de 2020. 